\title{
Didn't inhale? Time to reconsider aerosolized antibiotics in the treatment of ventilator-associated pneumonia
}

\author{
Daniel A. Sweeney ${ }^{1}$ and Andre C. Kali $\left.\right|^{2^{*}}$ (D) \\ See related research by Xu et al., https://ccforum.biomedcentral.com/articles/10.1186/s13054-018-2106-X
}

Keywords: Inhaled, Aerosolized, Antibiotics, Ventilator-associated pneumonia

"The War on Drugs" in the 1970s had an unintended effect on the illegal cannabis industry, increasing domestic production such that cannabis has become among the most profitable cash crops in the United States [1]. Legal barriers to cannabis use are also steadily crumbling: 30 states have legalized medical marijuana and nine states permit recreational use [2]. Yet despite its economic impact and increasing mainstream use, the safety and merits of cannabis consumption have not been rigorously studied. Is cannabis an effective antiepileptic or does it cause seizures? How is it possible that cannabis is touted as an anti-emetic, yet cannabinoid hyperemesis syndrome is reported in the medical literature? The answers to these questions likely relate to dose, mode of delivery, and patient selection-the very same questions at the root of whether inhaled antibiotics are an effective therapy for ventilator-associated pneumonia (VAP).

VAP, defined as pneumonia developing $48 \mathrm{~h}$ after intubation, is associated with increased intensive care unit (ICU) stay and duration of mechanical ventilation and may independently impact mortality $[3,4]$. The burden of VAP on the healthcare system is not trivial, with survey data suggesting that VAP represents close to $10 \%$ of all hospital-acquired infections [5]. The problem of VAP is more complex in light of the growing scourge of multidrug resistant (MDR) organisms. Coupled with a paucity of new antibiotics, clinicians and researchers have turned their attention to improving the delivery of

\footnotetext{
* Correspondence: akalil@unmc.edu

${ }^{2}$ Division of Infectious Diseases, Department of Medicine, University of Nebraska Medical Center, 985400 Nebraska Medical Center, Omaha, NE 68135, USA

Full list of author information is available at the end of the article
}

tried-and-true medications, including the use of extended intravenous effusions and aerosolized antibiotics. Inhaled antimicrobials have been used since the 1940s to treat various respiratory infections. Yet, only three aerosolized antibiotics (aztreonam, tobramycin, and colistin) have received either FDA or European Medicines approval and only for the treatment of infections in patients with cystic fibrosis [6].

The role of inhaled antibiotics for VAP has been studied in numerous independent small randomized trials enrolling-in sum-approximately 400 patients and described in various observational studies totaling nearly 700 patients. These studies encompass heterogeneous populations, infected with different MDR organisms, treated with various antibiotics administered as either a solo or adjunctive therapy, delivered via a variety of technologies (e.g., jet nebulizer, ultrasonic nebulizer, vibrating mesh nebulizer), and used different outcome endpoints $[7,8]$. Thus, interpreting these results is a challenging task. Alternatively, it is remarkable that most randomized or observational studies of inhaled antibiotics for VAP have shown some potential benefit (either mortality, clinical recovery, or microbiologic clearance) and low risk for harms such as systemic antibiotic toxicity or development of new antimicrobial resistance. In fact, the high peak concentration and the low systemic exposure of inhaled antibiotics may lead to less selective pressure and lower development to bacterial resistance than intravenous antibiotics.

In light of the challenges to interpret the current evidence on the efficacy of inhaled antibiotics, Xu et al. [9] performed both a standard and a network meta-analysis (NMA) involving randomized and observational studies to 
expand our understanding of the effect of inhaled antibiotics for the treatment of VAP. The findings from the standard meta-analysis suggest significant benefits from the adjunctive use of inhaled antibiotics compared to intravenous therapies alone in terms of both clinical recovery and microbiological eradication; adjunctive aerosolized antibiotic therapy conferred no differences regarding mortality and nephrotoxicity outcomes. Alternatively, the results of the NMA suggest that clinical recovery benefits, microbiological eradication, and survival were each associated with different aerosolized antibiotics. Hence, this comprehensive analysis suggests a potential benefit of inhaled antibiotics for patients with VAP, but not to a degree that would warrant clinicians deviating from the current American Thoracic Society (ATS)/Infectious Diseases Society of America (IDSA) recommendation that the use of both inhaled and systemic antibiotics should only be considered when the bacterial etiology of the pneumonia is due to MDR Gram-negative microorganisms sensitive only to aminoglycosides or polymyxins [3].

A coordinated effort to study inhaled antibiotics for the treatment of VAP is needed. And future investigations must pay particular attention to specific variables and study design characteristics. Patient selection is extremely important. There is no gold standard definition for VAP, and many prior studies of ICU patients with suspected pneumonia have been limited by the inclusion of patients who were not infected. Including objective measures such as hypoxia, severity scores, biomarkers, and rapid PCR diagnostics when defining the trial population could reduce this risk. The impact of the drug delivery systems also needs to be studied and should include currently available and inexpensive delivery systems such a jet nebulization so as to increase the chances of finding a broad reaching beneficial intervention. Finally, future trials should insist on hard and meaningful endpoints such as time on mechanical ventilation, ICU days, and mortality. Thus, the current body of evidence suggests that the case for inhaled antibiotics in VAP may have great potential and is worthy of study. But like the controversy surrounding medical and recreational marijuana use, clarity on the issue of inhaled antibiotics for VAP will only be achieved with prospective studies that take into consideration patient characteristics, drug dose, and mode of delivery and utilize objective endpoints.

\section{Acknowledgements}

None.

\section{Funding}

None.

Availability of data and materials Not applicable.
Authors' contributions

Both authors contributed equally to this manuscript. Both authors read and approved the final manuscript.

Ethics approval and consent to participate

Not applicable.

Consent for publication

Not applicable.

Competing interests

The authors declare that they have no competing interests.

\section{Publisher's Note}

Springer Nature remains neutral with regard to jurisdictional claims in published maps and institutional affiliations.

\section{Author details}

'Division of Pulmonary, Critical Care and Sleep Medicine, University of California, San Diego, CA, USA. ${ }^{2}$ Division of Infectious Diseases, Department of Medicine, University of Nebraska Medical Center, 985400 Nebraska Medical Center, Omaha, NE 68135, USA.

Received: 23 July 2018 Accepted: 24 September 2018

Published online: 05 December 2018

References

1. How pot has grown. https://www.nytimes.com/1995/02/19/magazine/howpot-has-grown.html. Accessed on 24 Aug 2018.

2. Medical Marijuana Research Hits Wall of U.S. Law. https://www.nytimes.com/ 2014/08/10/us/politics/medical-marijuana-research-hits-the-wall-of-federallaw.html. Accessed on 24 Aug 2018.

3. Kalil AC, Metersky ML, Klompas M, Muscedere J, Sweeney DA, Palmer LB, et al. Management of adults with hospital-acquired and ventilatorassociated pneumonia: 2016 clinical practice guidelines by the Infectious Diseases Society of America and the American Thoracic Society. Clin Infect Dis. 2016;63(5):e61-e111.

4. Muscedere JG, Day A, Heyland DK. Mortality, attributable mortality, and clinical events as end points for clinical trials of ventilator-associated pneumonia and hospital-acquired pneumonia. Clin Infect Dis. 2010;51(Suppl 1):S120-5.

5. Magill SS, Edwards JR, Bamberg W, Beldavs ZG, Dumyati G, Kainer MA, et al. Multistate point-prevalence survey of health care-associated infections. N Engl J Med. 2014;370(13):1198-208.

6. Quon BS, Goss CH, Ramsey BW. Inhaled antibiotics for lower airway infections. Ann Am Thorac Soc. 2014:11(3):425-34.

7. Dugernier J, Ehrmann S, Sottiaux T, Roeseler J, Wittebole X, Dugernier T, et al. Aerosol delivery during invasive mechanical ventilation: a systematic review. Crit Care. 2017;21(1):264.

8. Dhanani J, Fraser JF, Chan HK, Rello J, Cohen J, Roberts JA. Fundamentals of aerosol therapy in critical care. Crit Care. 2016;20(1):269.

9. Xu et al. Critical Care. 2018;22:301 